Check for updates

Cite this: RSC Adv., 2018, 8, 15825

Received 19th March 2018 Accepted 23rd April 2018

DOI: $10.1039 / \mathrm{c} 8 \mathrm{ra02383b}$

rsc.li/rsc-advances

\section{Organic dye-catalyzed radical ring expansion reaction $\dagger$}

\author{
Masato Deguchi, Akitoshi Fujiya, Eiji Yamaguchi, Norihiro Tada, (D) Bunji Uno \\ and Akichika Itoh (D) *
}

Herein, we reported an attractive method for synthesizing medium-sized rings that are catalyzed by erythrosine B under fluorescent light irradiation. This synthetic approach featured mild conditions, a facile procedure, a broad substrate scope, and moderate-to-good yields.
Medium-sized rings are present in numerous important natural products and pharmaceuticals. ${ }^{1}$ Therefore, several researchers have strived to develop various methods, including olefin metathesis, $^{2}$ fragmentation, ${ }^{3}$ and pericyclic reactions ${ }^{4}$ (Scheme 1(a)), for synthesizing these materials. Nevertheless, unfavorable transannular interactions and entropic factors typical of rings of this size make this task quite challenging. ${ }^{5}$ Thus, we believe that new methods need to be developed to solve these problems.

(a)

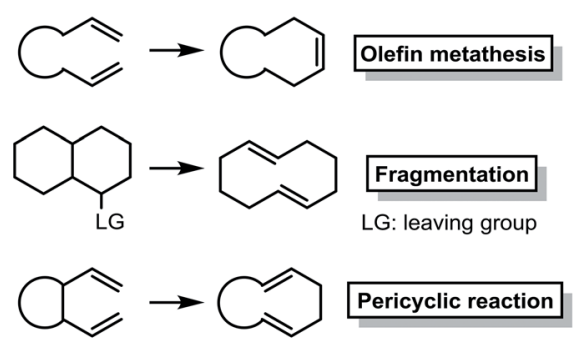

(b)

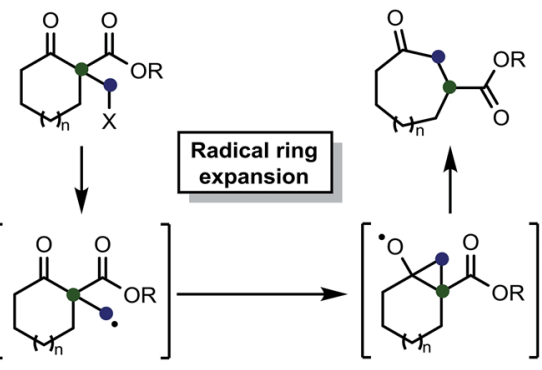

Scheme 1 (a) Examples of conventional approaches for the synthesis of medium-sized rings. (b) Beckwith-Dowd ring expansion reaction.

Gifu Pharmaceutical University, 1-25-4, Daigaku-nishi, Gifu 501-1196, Japan. E-mail: itoha@gifu-pu.ac.jp

$\dagger$ Electronic supplementary information (ESI) available: Experimental procedures, product characterization, time course of $\mathbf{1 a}$ and $2 \mathbf{a}$, emission spectrum of the fluorescent lamp, and detailed information of the DFT calculation. See DOI: $10.1039 / \mathrm{c} 8 \mathrm{ra0} 2383 \mathrm{~b}$
More than 30 years ago, the Beckwith-Dowd ring expansion reaction ${ }^{6}$ was introduced as a novel method to form mediumsized rings (Scheme 1(b)). This approach can be an attractive alternative to conventional strategies for synthesizing the abovementioned structures. Actually, the fact that no new unsaturated $\mathrm{C}-\mathrm{C}$ bonds are formed as part of this method renders hydrogenation processes unnecessary, thereby minimizing the impact of transformation on the substrate. Certainly, this approach could be applicable to the synthesis of natural products. ${ }^{7}$ However, the original method requires reagents, e.g., azobisisobutyronitrile (AIBN) or tributyltin hydride $\left(\mathrm{Bu}_{3} \mathrm{SnH}\right)$, that are difficult to handle. Some related methods that employ other reagents, including $\mathrm{Sm},{ }^{8} \mathrm{Zn}$ or In, ${ }^{9}$ $\mathrm{B}_{12}-\mathrm{TiO}_{2}$ hybrid catalyst, ${ }^{10}$ silane, ${ }^{11}$ and amines, ${ }^{12}$ have been reported. Recently, a few synthetic approaches based on photoinduced reactions have been developed. ${ }^{12 b, 12 d, 13} \mathrm{~A}$ previous study reported that even $\alpha$ - $(\omega$-carboxyalkyl) $\beta$-keto esters could be employed as relevant substrates. ${ }^{13}$

In this context, we aimed to establish a more efficient and facile method than conventional ones to prepare a broad range of medium-sized rings via a ring expansion reaction. We continuously investigated various photo-initiated reactions by employing a photosensitizer and a fluorescent lamp as a light source. ${ }^{14}$ For example, the CDC cross-coupling reaction ${ }^{14 a}$ and 1,3-dipolar cycloaddition/aromatization reaction ${ }^{14 d}$ under photooxidative reaction conditions have been reported. While investigating these reactions, we found that organic dyes induced electron transfer from amine substrates to molecular oxygen. ${ }^{14 a, 14 d}$ Thus, we envisioned that C-halogen bonds can be cleaved in the presence of a sacrificial amine using photosensitized substrates as a springboard. Herein, we reported a convenient and environmentally friendly method that employs a photo-induced reaction as part of the BeckwithDowd ring expansion route to synthesize medium-sized rings.

We initiated our study with the optimization of the reaction conditions (Table 1). Methyl 1-(iodomethyl)-2-oxocyclohexane1-carboxylate (1a) was chosen as a substrate. A mixture of $\mathbf{1 a}$ and different types of amines and photocatalysts was irradiated with four fluorescent lamps under a nitrogen atmosphere for 


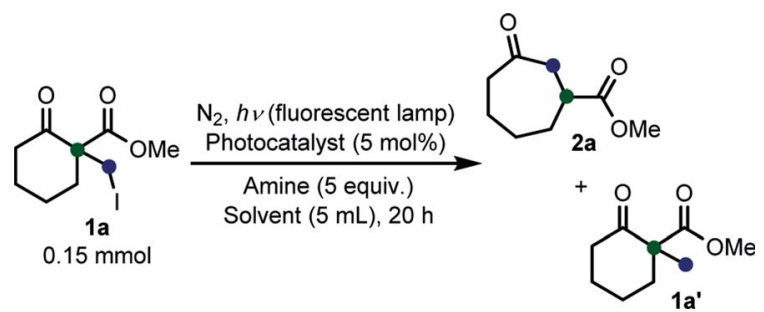

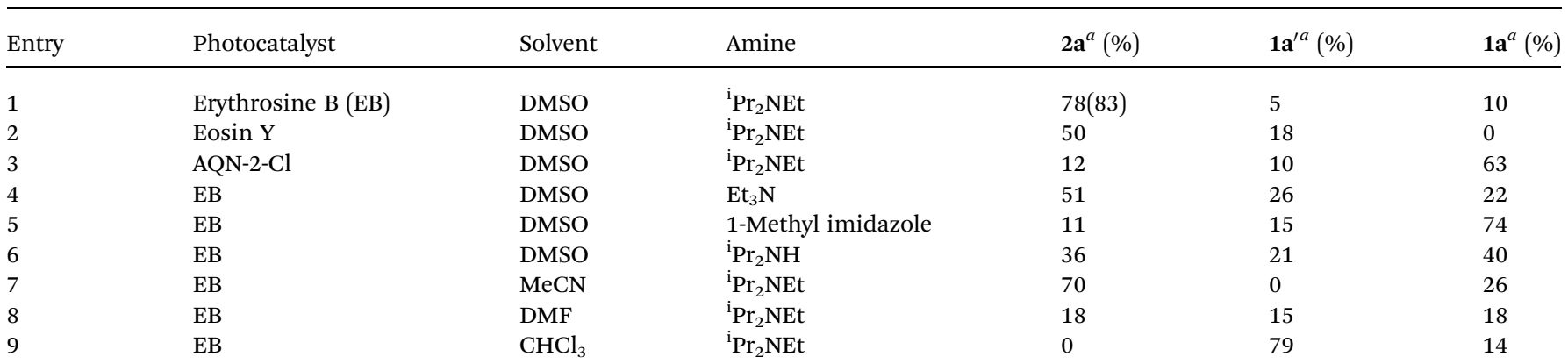

${ }^{a}$ Yields are determined by ${ }^{1} \mathrm{H}$ NMR spectroscopy using 1,1,2,2-tetrachloroethane as an internal standard. The number in parentheses denotes isolated yield.

$20 \mathrm{~h}$ in DMSO. After extensive investigations, we found that a combination of erythrosine $\mathrm{B}(\mathrm{EB})$ and ${ }^{\mathrm{i}} \mathrm{Pr}_{2} \mathrm{NEt}$ was the most efficient combination for this transformation, affording the desired product $2 \mathrm{a}$ in $83 \%$ isolated yield (entry 1$).{ }^{15}$ This result can be explained by two facts: (a) the maximum absorption of $\mathrm{EB}(\sim 520 \mathrm{~nm})^{16}$ coincides with the wavelength of the fluorescent lamp and (b) ${ }^{\mathrm{i}} \mathrm{Pr}_{2} \mathrm{NEt}$ is an effective reductive quencher $\left(E_{\mathrm{Ox}}\left({ }^{\mathrm{i}} \mathrm{Pr}_{2} \mathrm{NEt}^{\cdot+} /{ }^{\mathrm{i}} \mathrm{Pr}_{2} \mathrm{NEt}\right)=+0.68 \mathrm{~V}\right.$ vs. SCE; e.g.,$E_{\mathrm{Ox}}\left(\mathrm{NEt}_{3}{ }^{\cdot+} / \mathrm{NEt}_{3}\right)=$ $+0.99 \mathrm{~V} v s$. SCE). ${ }^{17 a, 17 b}$ In fact, when we employed other combinations of photocatalysts, amines, and solvents, 2a was obtained in a relatively lower yield. Furthermore, in our experiments, we recovered 1a and/or its undesired hydrogenation product $\mathbf{1 a}^{\prime}$ from the reaction mixture in substantial amounts (entries 2-9).

With the optimized reaction conditions in hand, we next explored the substrate scope of this transformation (Table 2). We found that compounds comprising 5-8-membered rings were suitable substrates for the reaction and gave the desired products in good yields (2a-2e). When we employed 1,2,3,4tetrahydro naphthalene-type substrate 1f, the desired reaction proceeded smoothly. On the other hand, indane-based substrate $1 \mathrm{~g}$ gave a mixture of the desired product and the aromatized product $(\mathbf{3 g})$. Due to the difficulty of achieving complete separation of the desired product and $\mathbf{3 g}$, we further investigated the reaction conditions in order to obtain a single product. Although the changes in the reaction time and in the composition of the overhead atmosphere did not substantially affect the course of the reaction, we found that the addition of 3 equiv. of $\mathrm{LiOH}$ led to the formation of the aromatized product $3 g$ exclusively in moderate yield. Furthermore, we tested whether compounds that contain the $\mathrm{C}-\mathrm{Br}$ bond could also be used as substrates for this reaction. When we applied the standard reaction conditions to substrate $\mathbf{1 h}$, the yield of the desired product $\mathbf{2} \mathbf{a}^{\prime}$ was around $10 \%$. However, adding a catalytic amount of $\mathrm{Ag}_{2} \mathrm{CO}_{3}$ and extending the reaction time increased the yield. Additionally, it is worth noting that this reaction could be carried out in an air atmosphere with almost no decrease in product yield. This result indicates that the presence of oxygen or water in the atmosphere above the reaction mixture has a negligible impact on in situ radical generation and subsequent steps to furnish the ring expanded product.

Scheme 2 summarizes the results of additional experiments conducted to investigate the substrate scope. We tested a substrate with an iodopropyl side chain, $\mathbf{1 i}$, and found that the addition of a silver salt and extension of the reaction time led to the formation of a tertiary alcohol with a fused ring, 3i, instead of the corresponding cyclononanone (eqn (1)). Additionally, we found that this reaction is applicable to substrates with ketones in open-chain moieties, such as $\mathbf{1 j}$ and 1k. Particularly, although $2 \mathbf{j}$ was volatile, and we needed to treat it carefully during isolation, these substrates gave the rearranged product in high yield (eqn (2) and (3)).

Next, we performed some experiments to elucidate the reaction mechanism (Scheme 3). We observed that no ring expansion product 2a was obtained when we omitted EB or ${ }^{\mathrm{i}} \mathrm{Pr}_{2} \mathrm{NEt}$ or photo-irradiation from the fluorescent lamps. Additionally, if we added 1 equiv. of TEMPO (2,2,6,6-tetramethylpiperidine 1-oxyl free radical), the desired product was obtained in low yield and the presence of a TEMPO-adduct was detected. ${ }^{18}$ This result confirms the idea that this reaction proceeds via a radical pathway.

Based on these results, previous reports on the BeckwithDowd ring expansion reaction, ${ }^{6}$ and recent reports of radical 
Table 2 Substrate scope

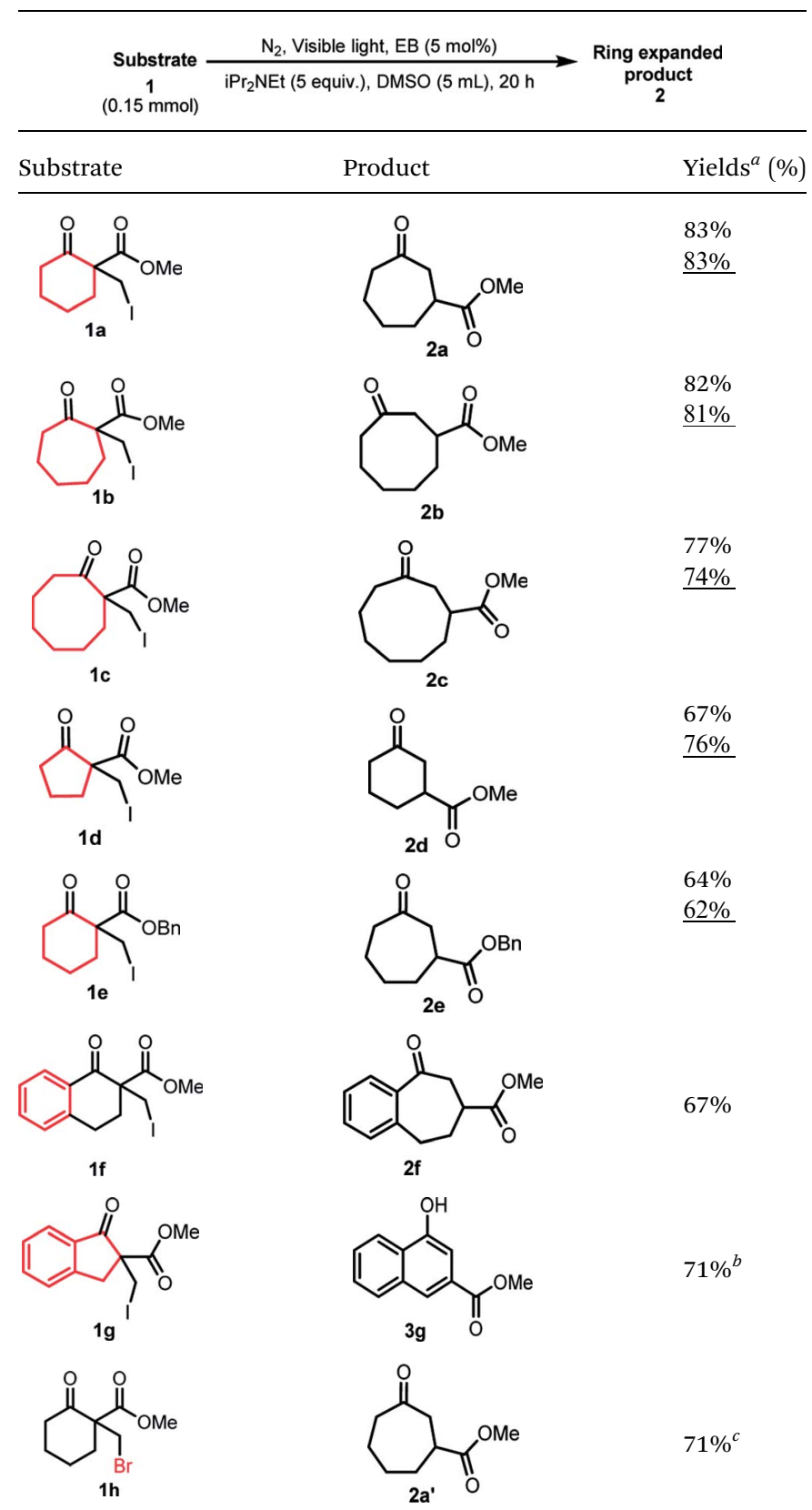

${ }^{a}$ Yields shown in the table are all pure, isolated yields. The underlined percentages are the yields when the reactions were performed under air atmosphere. ${ }^{b} 3$ equiv. of $\mathrm{LiOH}$ added. ${ }^{c} 5 \mathrm{~mol} \%$ of $\mathrm{Ag}_{2} \mathrm{CO}_{3}$ added, reaction time is $40 \mathrm{~h}$.

reactions set off by $\mathrm{C}$-halogen bond cleavage, ${ }^{17 b, 19}$ we inferred a plausible mechanistic pathway for the reaction, which is depicted in Scheme 4. The first step in the C-I bond cleavage reaction of 1a is photo-induced single electron transfer (SET) from the excited state of EB. In the experimental conditions employed, EB is considered to be a monoanionic $\left(\mathrm{EB}^{-}\right)$or dianionic $\left(\mathrm{EB}^{2-}\right)$ species because its commercially available disodium salt $\left(\mathrm{EBNa}_{2}\right)$ is added to the reaction mixture containing DIPEA without acidic treatment. To gain further insight into

<smiles>COC(=O)C(C)(CI)C(C)=O</smiles>

$\mathrm{N}_{2}, h v$ (fluorescent lamp) EB $(5 \mathrm{~mol} \%)$

${ }^{i} \mathrm{Pr}_{2} \mathrm{NEt}(5$ equiv.)

DMSO $(5 \mathrm{~mL}), 20 \mathrm{~h}$
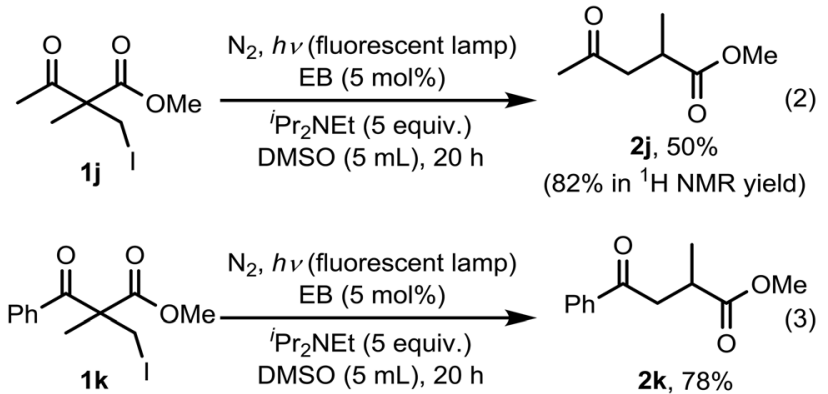<smiles>COC(=O)C(C)CC(=O)c1ccccc1</smiles>

Scheme 2 Applying the reaction conditions on substrates with threecarbon lateral chain and acyclic $\beta$-keto esters.

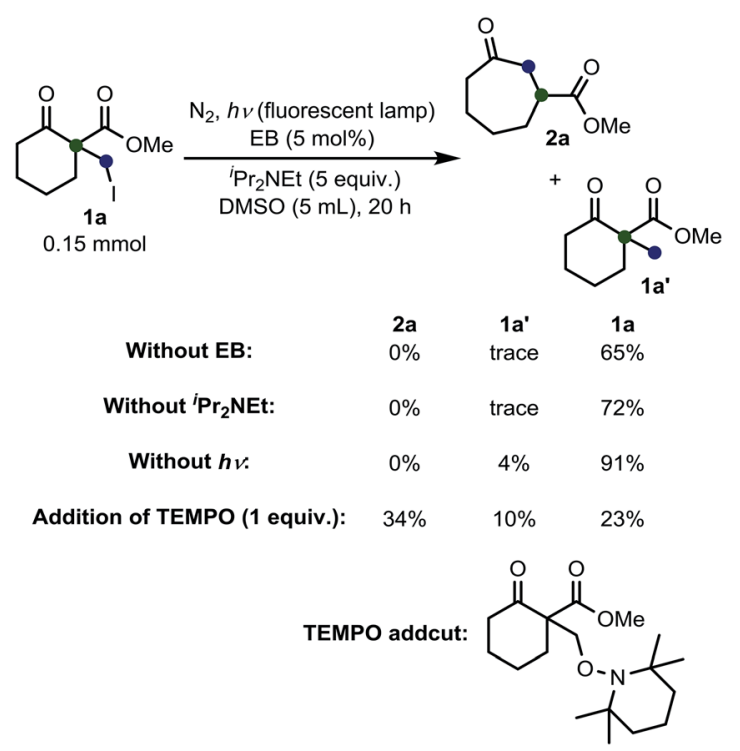

Scheme 3 Results of the control experiments.

this SET step, we calculated the Gibbs energies involved in the reaction between $1 \mathrm{a}$ and $\mathrm{EB}$ in a solution environment (solvent: DMSO; $\varepsilon=46.826$ ) simulated by the IEF-PCM model using the M06-2X functional. ${ }^{20}$ The standard Gibbs energy change $\left(\Delta G^{\circ}\right)$ calculated for the cleavage reaction of $1 \mathbf{a}$ with $\mathrm{EB}^{2-}\left(\mathbf{1 a}+\mathrm{EB}^{2-}\right.$ $\left.\rightarrow \mathbf{4 a}+\mathrm{I}^{-}+\mathrm{EB}^{\cdot-}\right)$ and with $\mathrm{EB}^{-}\left(\mathbf{1 a}+\mathrm{EB}^{-} \rightarrow \mathbf{4 a}+\mathrm{I}^{-}+\mathrm{EB}^{\cdot}\right)$ in the absence of light irradiation from the fluorescent lamp is 1.72 and $1.27 \mathrm{eV}$, respectively, as shown in Scheme 5. This indicates that these reactions are thermodynamically uphill electron-transfer processes. On the other hand, it is well known that the $\Delta G^{\circ}$ values for excited $\mathrm{EB}^{2-}\left(\mathrm{EB}^{2-*}\right) / \mathrm{EB}^{--}$and excited $\mathrm{EB}^{-}\left(\mathrm{EB}^{-*} / \mathrm{EB}^{*}\right)$ redox pairs are given by the amended RehmWeller equation with the excited-state energies $\left(E_{h \nu}\right)$ as $\Delta G^{\circ}\left(\mathrm{EB}^{2-*} / \mathrm{EB}^{\cdot-}\right)=\Delta G^{\circ}\left(\mathrm{EB}^{2-} / \mathrm{EB}^{\cdot-}\right)-E_{h \nu}$ and $\Delta G^{\circ}\left(\mathrm{EB}^{-*} / \mathrm{EB}^{\cdot}\right)=$ $\Delta G^{\circ}\left(\mathrm{EB}^{-} / \mathrm{EB}^{\circ}\right)-E_{h \nu}$, respectively. ${ }^{21,22}$ The reported excited-state energy of $\mathrm{EB}$ is $2.34 \mathrm{eV} ;^{16 a}$ thus, the $\Delta G^{\circ}$ values for the two 


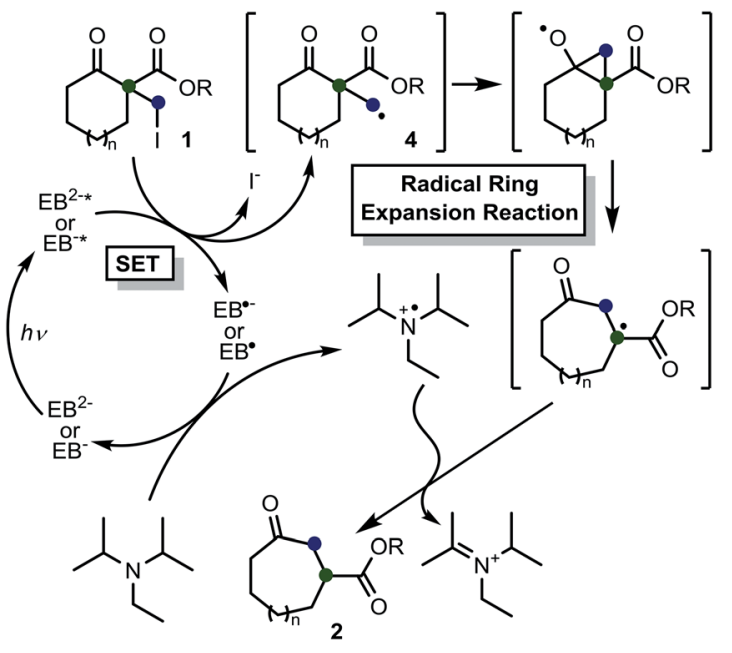

Scheme 4 Plausible reaction mechanism.

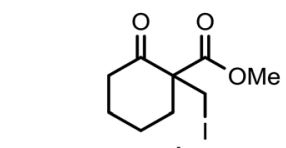

$$
G=-7467.145586
$$<smiles>O=C([O-])c1ccccc1-c1c2cc(I)c(=O)c(I)c-2oc2c(I)c(O)c(I)cc12</smiles>

$-28705.955829$

$$
\begin{aligned}
\Delta \mathrm{G}^{\circ} & =0.063044 \mathrm{~h} \\
& =1.715516 \mathrm{eV}
\end{aligned}
$$

$\mathrm{eV}$<smiles>COC(=O)C1(C)CCCCC1=O</smiles>

$-575.985974$

$+$

$1^{-}$ $-6891.276322$<smiles>O=C([O-])c1ccccc1-c1c2cc(I)c(=O)c(I)c-2oc2c(I)c(O)c(I)cc12</smiles>

$\mathrm{EB} *$ $-28705.776075$

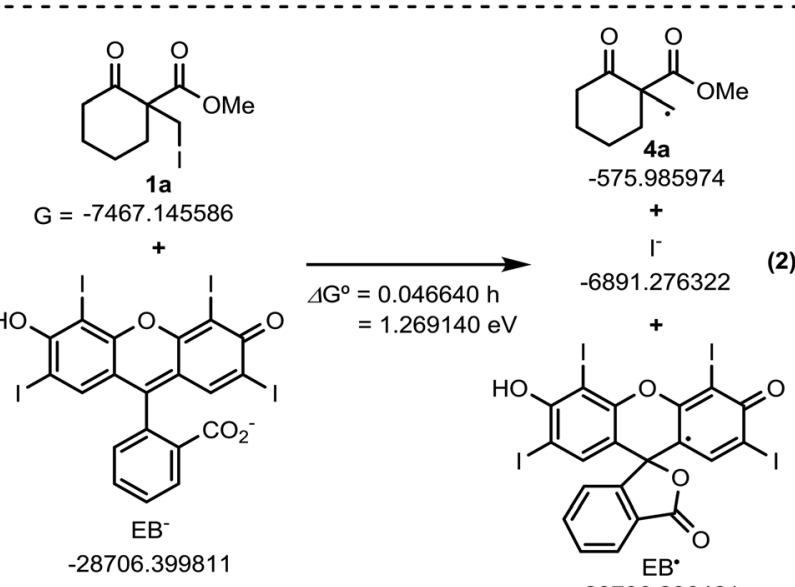

$-28706.236461$
Scheme 5 Standard Gibbs energies calculated for the species involved in the $\mathrm{C}-\mathrm{I}$ bond cleavage reaction with $\mathrm{EB}^{2-}$ (1) and $\mathrm{EB}^{-}$(2) using the M06-2X/PCM method with 6-31G (d) basis sets for hydrogen, carbon, and oxygen and the MIDI! basis set for iodine. Free energy corrections are made at standard conditions of $1 \mathrm{~atm}$ and $298.15 \mathrm{~K}$. mentioned $\mathrm{C}-\mathrm{I}$ bond cleavage reactions $\left(\mathbf{1 a}+\mathrm{EB}^{2-*} \rightarrow \mathbf{4 a}+\mathrm{I}^{-}+\right.$ $\mathrm{EB}^{\cdot-}$ and $\left.\mathbf{1 a}+\mathrm{EB}^{-*} \rightarrow \mathbf{4 a}+\mathrm{I}^{-}+\mathrm{EB}^{\circ}\right)$ involving photo-induced SET are -0.62 and $-1.07 \mathrm{eV}$, respectively, which indicate that the $E_{h \nu}$ value is sufficiently high for both bond cleavage reactions to be thermodynamically feasible. These results indicate that the cleavage reaction of $\mathbf{1}$ is governed by an exergonic $\mathrm{C}-\mathrm{I}$ bond cleavage mechanism involving SET from $\mathrm{EB}^{2-*}$ or $\mathrm{EB}^{-*}$. The primary radical 4 thus generated attacks the ketone, and then a rapid cyclopropane ring opening occurs. Meanwhile, the oxidized EB is reduced by the sacrificial amine, and the catalytic cycle of EB is completed. No particular $\mathrm{H}$ donor was necessary for this reaction to proceed; therefore, we assumed that an "extra" hydrogen atom of the product is derived from ${ }^{i} \operatorname{Pr}_{2}$ NEt. It believed that abstraction of a hydrogen atom from the trialkylammounium radical cation could occur, ${ }^{23}$ which strongly supports the above mechanism.

\section{Conclusions}

In conclusion, we have developed an environmentally friendly ring expansion reaction to synthesize medium-sized rings. This facile method involves the use of a fluorescent lamp as a source of irradiated light and an easy-to-handle photocatalyst. Attractively, this reaction proceeds under very mild conditions and is applicable to a broad spectrum of substrates. We believe that our method using a photo-triggered reaction course affords access to various pharmaceuticals and natural products. Studies to determine the mechanistic details of the reaction and expand its applicability to other useful substrates are currently underway in our laboratory.

\section{Conflicts of interest}

There are no conflicts to declare.

\section{Acknowledgements}

The authors would like to thank Enago (www.enago.jp) for the English language review.

\section{Notes and references}

1 (a) M. Hesse, Ring Enlargements in Organic Chemistry, $\mathrm{VCH}$, Weinheim, 1991; (b) M. C. Wani, H. L. Taylor, M. E. Wall, P. Coggon and A. T. McPhail, J. Am. Chem. Soc., 1971, 93, 2325-2327; (c) M. Norte, F. Cataldo, A. Sánchez and A. G. González, Tetrahedron Lett., 1993, 34, 5143-5146; (d) D.-F. Chen, S.-X. Zhang, L. Xie, J.-X. Xie, K. Chen, Y. Kashiwada, B.-N. Zhou, P. Wang, L. M. Cosentino and K.-H. Lee, Bioorg. Med. Chem., 1997, 5, 1715-1723.

2 For selected reviews, see: (a) J. Cossy, S. Arseniyadis and C. Meyer, Metathesis in Natural Product Synthesis, WileyVCH, Weinheim, 2010; (b) M. E. Maier, Angew. Chem., Int. Ed., 2000, 39, 2073-2077; (c) K. C. Nicolaou, P. G. Bulger and D. Sarlah, Angew. Chem., Int. Ed., 2005, 44, 4490-4527; (d) R. R. Schrock, Chem. Rev., 2009, 109, 3211-3226; (e) 
G. C. Vougioukalakis and R. H. Grubbs, Chem. Rev., 2010, 110, 1746-1787.

3 For recent examples of fragmentation reaction for construction of medium-sized rings, see: $(a) \mathrm{J}$. Tummatorn and G. B. Dudley, Org. Lett., 2011, 13, 1572-1575; (b) C. Kitsiou, J. J. Hindes, P. I'Anson, P. Jackson, T. C. Wilson, E. K. Daly, H. R. Felstead, P. Hearnshaw and W. P. Unsworth, Angew. Chem., Int. Ed., 2015, 54, 1579415798; (c) J. E. Hall, J. V. Matlock, J. W. Ward and J. Clayden, Angew. Chem., Int. Ed., 2016, 55, 11153-11157; (d) J. Koo, J. Kim and S. B. Park, Org. Lett., 2017, 19, 344-347. 4 For recent examples of pericyclic reaction for construction of medium-sized rings, see: (a) Y.-S. Lee, J.-W. Jung, S.-H. Kim, J.-K. Jung, S.-M. Peak, N.-J. Kim, D.-J. Chang, J. Lee and Y.-G. Suh, Org. Lett., 2010, 12, 2040-2043; (b) Y. Zou, L. Zhou, Z. Li and Q. Wang, Angew. Chem., Int. Ed., 2012, 51, 5647-5651; (c) L. Zhou, Z. Li, Y. Zou, Q. Wang, I. A. Sanhueza, F. Schoenebeck and A. Goeke, J. Am. Chem. Soc., 2012, 134, 20009-20012; (d) J. D. Osler, W. P. Unsworth and R. J. K. Taylor, Org. Biomol. Chem., 2013, 11, 7587-7594; (e) J. C. Orejarena Pacheco and T. Opatz, J. Org. Chem., 2014, 79, 5182-5192; (f) B. Zhou, L. Li, X.-Q. Zhu, J.-Z. Yan, Y.-L. Guo and L.-W. Ye, Angew. Chem., Int. Ed., 2017, 56, 4015-4019.

5 (a) G. Illuminati and L. Mandolini, Acc. Chem. Res., 1981, 14, 95-102; (b) M. A. Casadei, C. Galli and L. Mandolini, J. Am. Chem. Soc., 1984, 106, 1051-1056; (c) G. Molander, Acc. Chem. Res., 1998, 31, 603-609; (d) D. J. Faulkner, Nat. Prod. Rep., 1999, 16, 155-198; (e) B. M. Fraga, Nat. Prod. Rep., 2003, 20, 392-413; (f) J. Chang, J. Reiner and J. Xie, Chem. Rev., 2005, 105, 4581-4609; $(g)$ G. Bringmann, T. Gulder, T. A. M. Gulder and M. Breuning, Chem. Rev., 2011, 111, 563-639; (h) J. R. Donald and W. P. Unsworth, Chem.-Eur. J., 2017, 23, 8780-8799.

6 (a) A. L. J. Beckwith, R. Kazlauskas and M. R. Syner-Lyons, J. Org. Chem., 1983, 48, 4718-4722; (b) A. L. J. Beckwith, D. M. O'Shea, S. Gerba and S. W. Westwood, J. Chem. Soc., Chem. Commun., 1987, 666-667; (c) P. Dowd and S. C. Choi, J. Am. Chem. Soc., 1987, 109, 3493-3494; (d) P. Dowd and S. C. Choi, J. Am. Chem. Soc., 1987, 109, 6548-6549; (e) A. L. J. Beckwith, D. M. O'Shea and S. W. Westwood, J. Am. Chem. Soc., 1988, 110, 2565-2575; (f) P. Dowd and S. C. Choi, Tetrahedron Lett., 1989, 30, 6129-6132; $(g)$ P. Dowd and S. C. Choi, Tetrahedron, 1989, 45, 77-90; (h) P. Dowd and S. C. Choi, Tetrahedron Lett., 1991, 32, 565568; (i) W. Zhang and P. Dowd, Tetrahedron Lett., 1992, 33, 3285-3288; (j) H.-S. Oh, H. I. Lee and J. K. Cha, Org. Lett., 2002, 4, 3707-3709; ( $k$ ) J. Hierold and D. W. Lupton, Org. Lett., 2012, 14, 3412-3415for reviews, see:(l) P. Dowd and W. Zhang, Chem. Rev., 1993, 93, 2091-2115; $(m)$ L. Yet, Tetrahedron, 1999, 55, 9349-9403.

7 (a) E. Piers, M. Gilbert and K. L. Cook, Org. Lett., 2000, 2, 1407-1410; (b) H. Watanabe, M. Takano, A. Umino, T. Ito, H. Ishikawa and M. Nakada, Org. Lett., 2007, 9, 359-362; (c) Y. Liu and Y.-Y. Yeung, Org. Lett., 2017, 19, 1422-1425.

8 (a) E. Hasegawa, T. Kitazume, K. Suzuki and E. Tosaka, Tetrahedron Lett., 1998, 39, 4059-4062; (b) S. H. Chung,
M. S. Cho, Y. Choi, D. W. Kwon and Y. H. Kim, Synlett, 2001, 1266-1268; (c) H. Tsuchida, M. Tamura and E. Hasegawa, J. Org. Chem., 2009, 74, 2467-2475.

9 M. Sugi, D. Sakuma and H. Togo, J. Org. Chem., 2003, 68, 7629-7633.

10 (a) H. Shimakoshi, M. Abiru, S. Izumi and Y. Hisaeda, Chem. Commun., 2009, 6427-6429; (b) S. Izumi, H. Shimakoshi, M. Abe and Y. Hisaeda, Dalton Trans., 2010, 39, 3302-3307.

11 (a) M. Sugi and H. Togo, Tetrahedron, 2002, 58, 3171-3175; (b) E. Hasegawa, Y. Ogawa, K. Kakinuma, H. Tsuchida, E. Tosaka, S. Takizawa, H. Muraoka and T. Saikawa, Tetrahedron, 2008, 64, 7724-7728.

12 (a) E. Hasegawa, Y. Tamura and E. Tosaka, Chem. Commun., 1997, 1895-1896; (b) E. Hasegawa, A. Yoneoka, K. Suzuki, T. Kato, T. Kitazume and K. Yanagi, Tetrahedron, 1999, 55, 12957-12968; (c) E. Hasegawa, S. Takizawa, K. Iwaya, M. Kurokawa, N. Chiba and K. Yamamichi, Chem. Commun., 2002, 1966-1967; (d) E. Hasegawa, T. Ohta, S. Tsuji, K. Mori, K. Uchida, T. Miura, T. Ikoma, E. Tayama, H. Iwamoto, S. Takizawa and S. Murata, Tetrahedron, 2015, 71, 5494-5505.

13 K. Nishikawa, T. Ando, K. Maeda, T. Morita and Y. Yoshimi, Org. Lett., 2013, 15, 636-638.

14 (a) T. Yamaguchi, T. Nobuta, N. Tada, T. Miura, T. Nakayama, B. Uno and A. Itoh, Synlett, 2014, 25, 14531457; (b) A. Fujiya, T. Nobuta, E. Yamaguchi, N. Tada, T. Miura and A. Itoh, RSC Adv., 2015, 5, 39539-39543; (c) A. Okada, H. Yuasa, A. Fujiya, N. Tada, T. Miura and A. Itoh, Synlett, 2015, 26, 1705-1709; (d) A. Fujiya, M. Tanaka, E. Yamaguchi, N. Tada and A. Itoh, J. Org. Chem., 2016, 81, 7262-7270; (e) T. Yamaguchi, E. Yamaguchi and A. Itoh, Org. Lett., 2017, 19, 1282-1285.

15 Time course of the substrate $1 \mathbf{a}$ and the product 2a was shown in the ESI. $\dagger$

16 (a) M. A. Jhonsi, A. Kathiravan and R. Renganathan, J. Mol. Struct., 2009, 921, 279-284; (b) G. Sharifzade, A. Asghari and M. Rajabi, RSC Adv., 2017, 7, 5362-5371; (c) Y. Okuno and S. Cavagnero, J. Magn. Reson., 2018, 286, 172-187.

17 (a) U. Pischel, X. Zhang, B. Hellrung, E. Haselbach, P.-A. Muller and W. M. Nau, J. Am. Chem. Soc., 2000, 122, 2027-2034; (b) N. Esumi, K. Suzuki, Y. Nishimoto and M. Yasuda, Org. Lett., 2016, 18, 5704-5707.

18 See the ESI $\uparrow$ for the detail.

19 (a) E. Yoshioka, S. Kohtani, T. Jichu, T. Fukazawa, T. Nagai, Y. Takemoto and H. Miyabe, Synlett, 2015, 26, 265-270; (b) E. Yoshioka, S. Kohtani, T. Jichu, T. Fukazawa, T. Nagai, A. Kawashima, Y. Takemoto and H. Miyabe, J. Org. Chem., 2016, 81, 7217-7229.

20 C.-C. Chen, M.-Y. Wu, H.-Y. Chen and M.-J. Wu, J. Org. Chem., 2017, 82, 6071-6081. The detailed method and results of the calculation are shown in the ESI. $\dagger$

21 D. Rehm and A. Weller, Isr. J. Chem., 1970, 8, 259-271.

22 (a) S. Farid, J. P. Dinnocenzo, P. B. Merkel, R. H. Young and D. Shukla, J. Am. Chem. Soc., 2011, 133, 4791-4801; (b) S. Farid, J. P. Dinnocenzo, P. B. Merkel, R. H. Young, D. Shukla and G. Guirado, J. Am. Chem. Soc., 2011, 133, 11580-11587. 
23 (a) J. M. R. Narayanam, J. W. Tucker and C. R. J. Stephenson, J. Am. Chem. Soc., 2009, 131, 8756-8757; (b) A. G. Condie, J. C. González-Gómez and C. R. J. Stephenson, J. Am. Chem. Soc., 2010, 132, 1464-1465; (c) Y. Q. Zou, J. R. Chen, X. P. Liu, L. Q. Lu, R. L. Davis, K. A. Jørgensen and
W. J. Xiao, Angew. Chem., Int. Ed., 2012, 51, 784-788; (d) M. O. Ratnikov and M. P. Doyle, J. Am. Chem. Soc., 2013, 135, 1549-1557; (e) S. P. Pitre, C. D. McTiernan, H. Ismaili and J. C. Scaiano, J. Am. Chem. Soc., 2013, 135, 13286-13289. 